\title{
Some Natural Plants in Glycemic Amelioration in Streptozotocin Induced Rats
}

\author{
Fatma Farag Abdel Hamid ${ }^{1}$, Dawoud Fakhary Habib ${ }^{2}$, Nadia A. Mohamed ${ }^{* 2}$, \\ Marwa Glal El-deen ${ }^{1}$, Asem Metwally Abo Shanab ${ }^{3}$, Rabab Abdel Wahab ${ }^{4}$ \\ ${ }^{1}$ Biochemistry Department, Faculty of Science, Ain Shams University, Egypt \\ ${ }^{2}$ Medical Biochemistry Department, National Research Centre, Egypt \\ ${ }^{3}$ Immunogenetic, National Research Centre in Cairo, Egypt
}

${ }^{4}$ B.Sc. in Biochemistry 2010

\begin{abstract}
This work was done to study the effect of black and green coffee and cinnamon separately or together in double or triple combinations on the level of glucose and insulin in control and diabetic rats, to emphasize the effect of black and green coffee and cinnamon separately or together in hypolipidemia in control and diabetic rats. The study focused to deduce the better methods of herbal treatment comparison between treatments alone or by mixing herbs together. The statistical analysis of the results showed that insulin, Insulin sensitivity and HDL were increased in triple combination treated groups than double combination than single treated groups. In contrast, Glucose, Cholesterol, Triglyceride and HOMA IR were decreased in triple combination treated groups than double combination than single treated groups. Our study recommend using the triple combination treatment by cinnamon, green and black coffee due to it is the best group that acts as anti-hyperglycaemia, antihyperlipidemia and antioxidant effect
\end{abstract}

Keywords: Streptozotocin, Cinnamon, green and black coffee, glucose, insulin, lipids

\section{INTRODUCTION}

Diabetes Mellitus (DM) is a complex, chronic illness requiring continuous medical care with multifactorial risk-reduction strategies beyond glycemic control as it essentially affects all systems of the body. Ongoing patient self-management education and support are critical to preventing acute complications and reducing the risk of long-term complications. Significant evidence exists that supports a range of interventions to improve diabetes outcomes ${ }^{1}$. Several pathogenic processes are involved in the development of diabetes. These range from autoimmune destruction of the pancreatic $\beta$-cells with consequent insulin deficiency to abnormalities that result in resistance to insulin action. The basis of the abnormalities in carbohydrate, fat, and protein metabolism in diabetes is deficient action of insulin on target tissues ${ }^{2}$. Experimental diabetic models which could be studied with usage of genetic, chemical and surgical methods have been developed. The new experimental type 2 diabetes rat model is characterized with reduction of $40 \%$ of pancreatic beta islets. Streptozotocin (STZ), an antibiotic produced by Streptomyces achromogenes, is a commonly used agent to induce experimental type 1 diabetes. STZ can cause permanent damage to pancreatic $\beta$ cells and STZ treatment triggers destructive cellular pathways, including genotoxic DNA methylation and hydroxyl radical $(\mathrm{OH} \bullet)$ formation ${ }^{3}$.Under physiological circumstances, insulin regulates substrate utilization in multiple tissues, including the heart, skeletal muscle, liver, and adipose tissue. In the heart, insulin stimulates glucose uptake and oxidation and although it increases fatty acid (FA) uptake, it inhibits FA utilization for energy.Medicinal plants have been used since ancient times for the treatment and management of diabetic mellitus (DM) in traditional medicine systems of many cultures throughout the world ${ }^{4}$. Currently, medicinal plants continue to play an important role in the management of DM, especially in developing countries, where many people do not have access to conventional antidiabetic therapies ${ }^{5}$. In this regard it is worth to remind that one of the most popular diabetes medications, metformin, originates from the perennial herb Galegaofficinal is used in folk medicine to treat diabetes for hundreds of years ${ }^{6}$. 
The World Health Organization (WHO) recommended the use medicinal plants for the management of DM and further encouraged the expansion of the frontiers of scientific evaluation of hypoglycemic properties of diverse plant species ${ }^{7}$. Several species of medicinal plants used for the management of DM Worldwide have been evaluated. Some of the plants include: Cinnamomumcassie (Chinese cinnamon); Lauraceae, green coffee and black coffee.Cinnamon is a plant with scientific name - cinnamomumzelanicum and general name - cinnamon. This evergreen shrub belongs to the lauraceae family endemic to Sri Lanka and Southeast regions of India. This plant is one of the oldest medicinal herbs which have been used in traditional medicine as an important drug. Different parts of this plant including its bark have many therapeutic effects such as strengthening of the heart, stomach, intestines, improvement of kidney function, and increase in libido ${ }^{8}$. The volatile oil from cinnamon contains more than $98 \%$ cinnamaldehyde and that it confers dose dependent, significant protection against alloxan induced renal damage ${ }^{9}$.Cinnamon is used against important body pathogens including Escherichia coli, helicobacter pylori, and candida albicans due to its anti-fungal and anti-bacterial properties ${ }^{10}$. Consumption of this spice inhibits the oxidation of organic matter in body and reduces free radicals due to its potent antioxidant effect ${ }^{11}$. Kamath et al. ${ }^{12}$ showed that cinnamon extract is effective in healing wounds made on Wistar rats. Other therapeutic effects of this plant like treatment of nausea, diarrhea, and enhancement of cognitive power have been reported ${ }^{13}$. Notably, cinnamon was not able to exert significant effects in type 1 diabetic patients while its insulin-like effects were present in type 2 diabetic patients ${ }^{14}$. Interestingly, cinnamon extract was described as beneficial in Alzheimer's disease by reducing $\beta$-amyloid oligomerization and cognitive decline ${ }^{15}$ and cinnamon further prevented glutamate-induced neuronal death in cultured cerebellar granule cells ${ }^{16}$. Moreover, researchers have shown that aqueous cinnamon extract inhibits the proliferation of acute lymphoid leukemia cell line ${ }^{17}$.We tried in this study to find out the possible effect of aqueous cinnamon extract as anti-hyperglycaemic, and anti-hyperlipidemic herb.The histological preparations of kidney from the aqueous extract of Cinnamon treated and control rats showed that the various histological segments of kidney tubules were well preserved; no clinical signs of toxicity were observed in any of the groups during the course of the experiment and there were no significant changes when compared with the control ${ }^{18}$. Coffee is among the most widely consumed pharmacologically active beverages in the world. Caffeine is the most widely consumed psychoactive substance. Coffee is rich in phenolic compounds with a strong antioxidant activity ${ }^{19}$.Delgado-Andrade and Morales, ${ }^{20}$ found that regular drinking of coffee can reduce the oxidation of human Low-Density Lipoprotein (LDL) and the oxidation of LDL, decreasing the risk of atherosclerosis.Gaafar et al., ${ }^{21}$, found that, the concentration of plasma insulin of diabetic rats decreased in comparison to the control group. Green and light coffee bean supplemented to the diet of experimental diabetic groups significantly increased the insulin concentration in plasma compared to the diabetic group and the same with normal control group.

In the present study we investigated the effects ofblack and green coffee and cinnamon separately or together in double or triple combinations on the level of glucose, insulin and hypolipidemia in control and diabetic rats. The study focused to deduce the better methods of herbal treatment comparison between treatments alone or by mixing herbs together.

\section{MATERIAL AND MeTHODS}

\subsection{Animals}

Sixty four normal female albino rats weighting 150-200 g were obtained from the animal house of National Research Centre, Egypt. The animals were housed in individual suspended stainless steel cages in a controlled environment $\left(22-25^{\circ} \mathrm{C}\right)$ and 12 hour light, 12 hour dark with food and water available in national research center and left for 1 week for acclimatization prior to the start of the experiment.

The experimental design was approved by the institutional animal ethics committee. All rats used in the following experiments were subject to the Guiding Principles for the care and use of laboratory animals and the recommendations of the declaration of Helsinki.

Diabetes was induced in the overnight fasted rats by a single subcutaneous injection of streptozotocin $(50 \mathrm{mg} / \mathrm{kg}$ body weight) dissolved in citrate buffer $(\mathrm{pH}=4.5)$. Normal control rats received $50 \mathrm{mg} / \mathrm{kg}$ body weight citrate buffer only as vehicle. Fasting blood sugar was estimated after 72 hours to confirm the development of diabetes ${ }^{22}$. The fasting blood sugar was estimated after 3 days from all 
rat tail veins by glucometer to confirm the development of diabetes mellitus and then rats were divided into eight groups control, diabetic control and 6 diabetic groups were treated with cinnamon, green and black coffee aqueous extracts single and mixed after diabetes was induced.

\subsection{Chemicals}

Streptozotocin (STZ) was purchased from Sigma Chemicals Company, St, Louis, USA and cinnamon, Green coffee and black coffee were purchased from local market (Cairo, Egypt).

\subsection{Preparation of Natural Compounds Extracts}

For rats administrated single herbs, 10grams of each ground natural compound (black and green coffee, cinnamon) were added to $100 \mathrm{ml}$ of boiling distilled water then lift to cool and each rat is administered by gavage ( $4 \mathrm{ml}$ supernatant $/ \mathrm{kg} / \mathrm{day}$ ) for 90 days .

\subsection{Experimental Design and Animal Grouping}

Sixty four female albino rats were weighed and divided into eight equal groups; all were treated orally one time daily for 90 days.

Group 1: untreated controls; Group 2: diabetic control; Group 3: group will be rendered STZ induced diabetic rats; Group 4: group will be rendered STZ induced diabetic rats; Group 5: group will be rendered STZ induced diabetic rats; Group 6: group will be rendered STZ induced diabetic; Group 7: group will be rendered STZ induced diabetic, Group 8: group will be rendered STZ induced diabetic rats

\subsection{Blood Collection}

After 3 months of the experiment, from the treatments, 6 rats from each group were fasted overnight before blood sampling and sacrificed under diethyl ether anesthesia. Blood samples were collected and allowed to coagulate at room temperature then centrifuged at $3000 \mathrm{rpm}$ for 30 minutes. The clear, non haemolysed supernatant sera were quickly removed and stored at $-20 C^{\circ}$ for subsequent biochemical analysis. The following parameters were estimated:-

\subsubsection{Determination of Fasting Blood Glucose}

This was performed according to the method of Caraway et al., ${ }^{23}$. The kit was supplied from Spectrum (Egyptian company of Bio technology).

\subsubsection{Determination of Plasma Insulin Level}

This was performed according to the method of Eastham, ${ }^{24}$. The kit was supplied from glory company, USA.

\subsubsection{Insulin Resistance}

Insulin resistance was calculated from the equation according to Wallace et al., ${ }^{25}$ :

Insulin resistance $=$ Fasting glucose $(\mathrm{mg} / \mathrm{dl}) \times$ fasting insulin $/ 22.5(\mu \mathrm{IU} / \mathrm{ml})$.

\subsubsection{Determination of Cholesterol}

This was performed according to the method of Rautela and Liedtke ${ }^{26}$. The kit was supplied from Siemens Company.

\subsubsection{Determination of Triglyceride}

This was performed according to the method Rifai et al., ${ }^{27}$. The kit was supplied from Siemens Company.

\subsubsection{Determination of High Density Lipoprotein Cholesterol (HDL-Cholesterol)}

This was performed according to the method of Genest ${ }^{28}$. The kit was supplied from Siemens Company.

\subsection{Statistical Analysis}

The collected data were coded, tabulated, and statistically analyzed using IBM SPSS statistics (Statistical Package for Social Sciences) software version 22.0, IBM Corp., Chicago, USA, 2013 
Fatma Farag Abdel Hamid et al.

Descriptive statistics were done for quantitative data as minimum\& maximum of the range as well as mean \pm SD (standard deviation) for quantitative parametric data. Inferential analyses were done for quantitative variables using paired t-test in cases of two dependent groups with parametric data, ANOVA Test for more than two independent groups with post hoc Tukey HSD test. While correlations were done using Pearson correlation for numerical parametric data. The level of significance was taken at $\mathrm{P}$ value $<0.050$ is significant, otherwise is non-significant.

\section{RESULTS}

The mean value level of FBS before treatment in diabetic group was significantly increased $(p=0.001)$ compared to control group (table 1, fig 1).

Table1. and fig1. Fasting blood glucose $(\mathrm{mg} / \mathrm{dl})$ before treatment indifferent studied groups

\begin{tabular}{|l|l|l|l|}
\hline Group & Mean \pm SD & Range & HG \\
\hline Non-DM control & $91.7 \pm 11.7$ & $80.0-110.0$ & $\mathrm{a}$ \\
\hline DM control & $446.7 \pm 70.0$ & $350.0-550.0$ & $\mathrm{~b}$ \\
\hline B. coffee & $455.0 \pm 65.3$ & $380.0-560.0$ & $\mathrm{~b}$ \\
\hline G. coffee & $465.8 \pm 74.9$ & $395.0-570.0$ & $\mathrm{~b}$ \\
\hline Cinnamon & $458.3 \pm 88.2$ & $360.0-590.0$ & $\mathrm{~b}$ \\
\hline B. coffee \& cinnamon & $448.3 \pm 66.8$ & $370.0-550.0$ & $\mathrm{~b}$ \\
\hline G. coffee and cinnamon & $469.5 \pm 72.5$ & $390.0-560.0$ & $\mathrm{~b}$ \\
\hline B, G coffee \& cinnamon & $461.5 \pm 77.1$ & $350.0-560.0$ & $\mathrm{~b}$ \\
\hline
\end{tabular}

HG: Homogenous groups have the same letter(TukeyHSD post ANOVA test) that between groups which nonsignificant difference between them.Number of cases $=8$, Significant $P$ value $=0.001 . P^{a}$ Significant difference compared to diabetic group and treated groups. $P^{b}$ Significant difference compared to control groups.

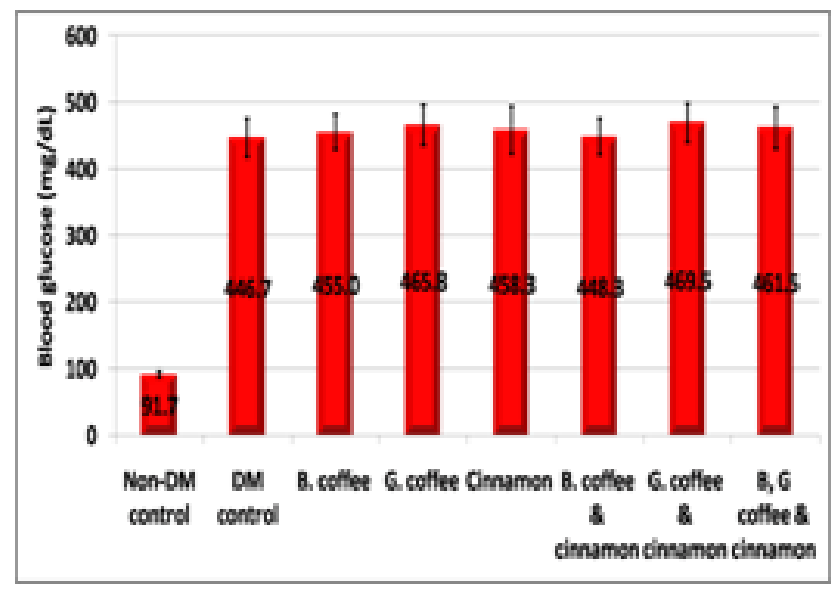

The mean value level of fasting blood sugar after treatment was significantly decreased in treated groups ( $\mathrm{p}=0.001$ ) compared to diabetic group (table 2, fig 2).

Table2. and fig2. Fasting blood glucose ( $\mathrm{mg} / \mathrm{dl})$ after treatment indifferent studied groups

\begin{tabular}{|l|l|l|l|}
\hline Group & Mean \pm SD & Range & HG \\
\hline Non-DM control & $95.5 \pm 8.8$ & $82.0-106.0$ & a \\
\hline DM control & $366.3 \pm 59.2$ & $258.0-414.0$ & b \\
\hline B. coffee & $250.7 \pm 20.6$ & $226.0-281.0$ & c \\
\hline G. coffee & $237.2 \pm 18.7$ & $210.0-254.0$ & c \\
\hline Cinnamon & $235.3 \pm 17.2$ & $212.0-262.0$ & c \\
\hline B. coffee \& cinnamon & $184.7 \pm 16.7$ & $164.0-203.0$ & d \\
\hline G. coffee and cinnamon & $177.3 \pm 29.8$ & $126.0-203.0$ & d \\
\hline B, G coffee \& cinnamon & $112.2 \pm 11.4$ & $99.0-129.0$ & a \\
\hline
\end{tabular}

HG: Homogenous groups have the same letter (Tukey HSD post ANOVA test) that between groups which nonsignificant difference between them. Number of cases $=8$, Significant $P$ value $=0.001$. $P^{a}$ Significant difference compared to diabetic group, single and double treated groups. $P^{b}$ Significant difference compared to control, single, double and triple groups. $P^{c}$ Significant difference to control, diabetic, double and triple groups. $P^{d}$ Significant difference to control, diabetic, single and triple groups. 


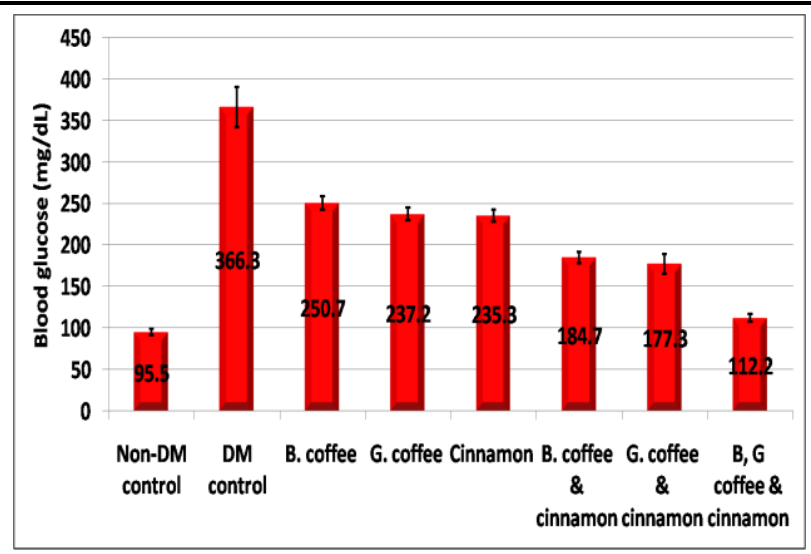

The mean value level of insulin in diabetic group was significantly decreased $(\mathrm{p}=0.001)$ compared to control group.In contrast, the double or triple combinationtreated groups were significantly increased $(\mathrm{p}=0.001)$ compared to diabetic group or in comparing to singletreated groups (table 3$)$. Where the mean value level of insulin resistance (HOMA-IR) in diabetic group was significantly increased $(\mathrm{p}=0.001)$ compared to control group. The triple combination treated group is significantly decreased $(\mathrm{p}=0.001)$ compared with diabetic group or with single treated groups (table 4).

Table3. Serum insulin ( $\mu I U / L)$ after treatment indifferent studied groups

\begin{tabular}{|l|l|l|l|}
\hline Group & Mean \pm SD & Range & HG \\
\hline Non-DM control & $9.0 \pm 0.5$ & $8.3-9.5$ & a \\
\hline DM control & $4.1 \pm 0.4$ & $4.4-5.6$ & b \\
\hline B. coffee & $6.1 \pm 1.4$ & $4.8-8.6$ & b, c \\
\hline G. coffee & $6.4 \pm 1.0$ & $5.3-7.9$ & b, c, d \\
\hline Cinnamon & $6.0 \pm 0.7$ & $4.1-6.9$ & b, c \\
\hline B. coffee \& cinnamon & $8.0 \pm 1.3$ & $5.9-9.8$ & a, d \\
\hline G. coffee and cinnamon & $7.4 \pm 0.8$ & $6.4-8.8$ & a, c, d \\
\hline B, G coffee \& cinnamon & $8.7 \pm 0.7$ & $7.6-9.7$ & a \\
\hline
\end{tabular}

HG: Homogenous groups have the same letter (Tukey HSD post ANOVA test) that between groups which nonsignificant difference between them. Number of cases $=8$, Significant $P$ value $=0.001$. $P^{a}$ Significant difference compared to diabetic, single and double combination treated groups. $P^{b}$ Significant difference compared to control, double and triple groups. $P^{c}$ Significant difference to control, diabetic, black coffee \&cinnamon double combination and triple groups. $P^{d}$ Significant difference to control, diabetic, black coffee, cinnamon single groups and triple groups

Table4. Serum insulin resistance after treatment indifferent studied groups

\begin{tabular}{|l|l|l|l|}
\hline Group & Mean \pm SD & Range & HG \\
\hline Non-DM control & $38.1 \pm 3.9$ & $34.7-43.1$ & A \\
\hline DM control & $83.1 \pm 16.5$ & $59.1-103.8$ & B \\
\hline B. coffee & $68.7 \pm 21.0$ & $52.4-107.5$ & b, c \\
\hline G. coffee & $67.3 \pm 10.0$ & $56.9-84.4$ & b, c \\
\hline Cinnamon & $63.2 \pm 8.2$ & $51.3-70.2$ & b, c, d \\
\hline B. coffee \& cinnamon & $66.1 \pm 15.7$ & $42.9-88.4$ & b, c, d \\
\hline G. coffee and cinnamon & $58.3 \pm 10.0$ & $44.6-70.1$ & a, c, d \\
\hline B, G coffee \& cinnamon & $43.4 \pm 4.9$ & $38.7-51.8$ & a, d \\
\hline
\end{tabular}

HG: Homogenous groups have the same letter (Tukey HSD post ANOVA test) that between groups which nonsignificant difference between them. Number of cases $=8$, Significant $P$ value $=0.001$. $P^{a}$ Significant difference compared to diabetic, single and black coffee\& cinnamon double combination treated group. $P^{b}$ Significant difference compared to control and triple groups. $P^{c}$ Significant difference to control, diabetic and triple groups. $P^{d}$ Significant difference to diabetic, single treated groups and double combination treated groups.

The mean value level of serum cholesterol and triglycerides in diabetic group single treated groups were significantly increased $(\mathrm{p}=0.001)$ compared to control group or in comparing of single treated group with diabetic group. However, the triple combination treated group, the mean value level of serum cholesterol was significantly decreased in compared to diabetic control or single treated groups or double combination treated groupstable (5) and table (6). 
Fatma Farag Abdel Hamid et al.

Table5. Serum cholesterol $(\mathrm{mg} / \mathrm{dl})$ after treatment indifferent studied groups

\begin{tabular}{|l|l|l|l|}
\hline Group & Mean \pm SD (Cholest.) & Range & HG \\
\hline Non-DM control & $103.9 \pm 9.9$ & $87.7-113.4$ & a \\
\hline DM control & $179.8 \pm 26.6$ & $131.1-201.3$ & b \\
\hline B. coffee & $150.1 \pm 12.3$ & $135.6-168.6$ & c \\
\hline G. coffee & $143.8 \pm 13.6$ & $120.0-158.4$ & $\mathrm{c}, \mathrm{d}$ \\
\hline Cinnamon & $143.1 \pm 11.1$ & $127.2-159.2$ & $\mathrm{c}, \mathrm{d}$ \\
\hline B. coffee \& cinnamon & $125.6 \pm 11.4$ & $111.5-138.0$ & $\mathrm{c}, \mathrm{d}$ \\
\hline G. coffee and cinnamon & $121.5 \pm 19.9$ & $88.6-140.0$ & $\mathrm{a}, \mathrm{d}$ \\
\hline B, G coffee \& cinnamon & $108.8 \pm 10.2$ & $97.0-126.4$ & $\mathrm{a}$ \\
\hline
\end{tabular}

Table6. Serum Triglyceride after $(\mathrm{mg} / \mathrm{dl})$ treatment in different studied groups

\begin{tabular}{|l|l|l|l|}
\hline Group & Mean \pm SD & Range & HG \\
\hline Non-DM control & $96.3 \pm 6.6$ & $88.0-104.0$ & A \\
\hline DM control & $170.2 \pm 25.8$ & $123.4-192.1$ & B \\
\hline B. coffee & $136.0 \pm 11.3$ & $122.0-151.7$ & C \\
\hline G. coffee & $137.9 \pm 9.9$ & $121.8-147.3$ & C \\
\hline Cinnamon & $142.4 \pm 10.8$ & $130.7-160.2$ & C \\
\hline B. coffee \& cinnamon & $127.6 \pm 10.8$ & $111.5-140.8$ & C \\
\hline G. coffee and cinnamon & $123.0 \pm 20.2$ & $88.5-142.1$ & a, c \\
\hline B, G coffee \& cinnamon & $100.5 \pm 10.7$ & $88.1-117.0$ & A \\
\hline
\end{tabular}

HG: Homogenous groups have the same letter (Turkey HSD post ANOVA test) that between groups which nonsignificant difference between them. Number of cases $=8$, Significant $P$ value $=0.001 . P^{a}$ Significant difference compared to diabetic, single and black coffee \&cinnamon double combination treated groups. $P^{b}$ Significant difference compared to control, single, double combination treated group and triple groups. $P^{c}$ Significant difference to control, diabetic and triple groups

The mean value level of serum HDL-cholesterol in diabetic group was significantly decreased $(\mathrm{p}=0.001)$ compared with control group.Alternatively, the mean value level of serum HDL-cholesterol in the triple combination treated group is significantly increased $(\mathrm{p}=0.001)$ compared with diabetic group or with single treated groups (table 7).

Table7. Serum HDL-c after ( $\mathrm{mg} / \mathrm{dl})$ treatment in different studied groups

\begin{tabular}{|l|l|l|l|}
\hline Group & Mean \pm SD & Range & HG \\
\hline Non-DM control & $55.9 \pm 5.6$ & $47.6-63.0$ & $\mathrm{a}$ \\
\hline DM control & $28.5 \pm 3.9$ & $23.5-34.7$ & $\mathrm{~b}$ \\
\hline B. coffee & $40.4 \pm 3.4$ & $36.2-45.0$ & $\mathrm{c}, \mathrm{d}$ \\
\hline G. coffee & $38.4 \pm 3.8$ & $33.4-43.2$ & $\mathrm{c}, \mathrm{d}$ \\
\hline Cinnamon & $37.6 \pm 1.7$ & $36.1-40.2$ & $\mathrm{c}$ \\
\hline B. coffee \& cinnamon & $45.3 \pm 3.9$ & $39.4-49.7$ & $\mathrm{~d}$ \\
\hline G. coffee and cinnamon & $44.8 \pm 4.2$ & $39.7-49.5$ & $\mathrm{~b}, \mathrm{c}, \mathrm{d}$ \\
\hline B, G coffee \& cinnamon & $51.6 \pm 4.4$ & $45.6-58.1$ & $\mathrm{a}, \mathrm{d}$ \\
\hline
\end{tabular}

HG: Homogenous groups have the same letter (Tukey HSD post ANOVA test) that between groups which nonsignificant difference between them. Number of cases $=8$, Significant $P$ value $=0.001 . P^{a}$ Significant difference compared to diabetic, single and double combination treated groups. $P^{b}$ Significant difference compared to control, single, black and cinnamon double combination treated group and triple groups. $P^{c}$ Significant difference to control, cinnamon single treated group, black coffee\& cinnamon double combination and triple groups. $P^{d}$ Significant difference to control, diabetic, cinnamon single treated group.

\section{DisCUSSION}

Type 2 diabetes mellitus is a major endocrine disorder and a deadly disease in human beings 29 . According to the recent estimations, the prevalence of diabetes in the world, would reach to 552 million people in $2030^{30}$. This disease is characterized by hyperglycemia, atherosclerosis, and abnormal lipid profile and also induces several chronic complications such as retinopathy, nephropathy, and neuropathy that results in burdening heavy load on these patients andsociety ${ }^{31}$. Dyslipidemia, a main risk factor for cardiovascular diseases as well as increase in generation of reactive oxygen species (ROS) and occurrence of oxidative stress which results in destruction of insulin producing $\beta$-cells in pancreatic langerhans islets, all have critical role in pathogenesis and progression of diabetes mellitus ${ }^{32}$. Although chemical antidiabetic drugs such as biguanides and sulphonylureas are available at the present time, they might cause several side effects e.g. 
hypoglycemia, liver toxicity, dyslipidemia and increase in blood pressure ${ }^{33}$. Since using of medicinal plants is more financial, and they have different varieties of effective compounds as well as lower side effects in comparison to synthetic drugs and also because of recommendations of World Health Organization (WHO), in recent years, there has been renewed interest in using hypoglycemic traditional plants ${ }^{34}$. There are many medicinal herbs which have been recommended for the treatment of diabetes ${ }^{35}$.In the present study, STZ produced a significant increase in blood glucose and insulin resistance levels followed by decrease insulin sensitivity along with a reduction in insulin levels in diabetic group compared to control group, these results were in agreement with ${ }^{36}$ who indicated that, STZ- induced diabetes produced a significant increase in fasting glucose levels that was associated with decrease in serum insulin levels.Also, these results in agreement with ${ }^{37}$ who found that Streptozotocin induced diabetes area well-documented model of experimental diabetes. It can begin an autoimmune process that results in the destruction of the Langerhans islets beta cells and results in the toxicity of beta cells ${ }^{38}$.

In our study, the level of fasting blood sugar after treatment significantly decreased this result in agreement with ${ }^{39}$ who reported that,Cinnamon lowered blood glucose, total cholesterol, and triglyceride levels in diabetic mice.The treatment by cinnamon may enhance glucose uptake by activating insulin receptor (IR) kinase activity, autophosphorylation of IR, glycogen synthesis and glycogen synthase activityIn vitro studies.

Awater-soluble polyphenol type-A polymer isolated from cinnamon has been shown to enhance insulin activity ${ }^{40}$. Many authors reported that cinnamon reduced postprandial glucose levels in human by delaying gastric emptying ${ }^{41}$ decreasing glucose absorption ${ }^{39}$, increasing the insulin sensitivity and glucose uptake in adipocytes ${ }^{42}$, as well as regulating glucose transporter and insulin-signaling gene expressionin adipocytes ${ }^{43}$.

In the present study,the levels of insulin sensitivity in the cinnamon treated groups was significantly increased, this resultwas in agreement with $^{44}$ who reported that Cinnamon supplementation facilitates glucose disposal in healthy humans, which may be achieved by enhancing:(1) Insulin sensitivity via increased phosphorylation of signaling proteins and(2) Insulin sensitive glucose transporter 4mediated glucose uptake into muscle cells.

Shearer, etal., ${ }^{45}$ found that, the administration of a decaffeinated coffee extract (DECAF) and a synthetic quinide, 3,4-diferuloyl-1,5-quinolactone (DIFEQ) increased whole body insulin action. This increase was not due to augmentation of skeletal muscle glucose uptake, and it is hypothesized that liver is the site at which DIFEQ acts to improve insulin action. These results support previous findings suggesting that coffee contains biologically active compounds other than caffeine that alter glucose metabolism.Type 2 diabetes is commonly associated with dyslipidemiawhich is a risk factor for the development of $\mathrm{CVD}^{46}$. This is supported by our present study. Fromthis study, there was a marked increase in the lipidcontent of serum in streptozotocin induced diabetic rat.This is due to the increased mobilization of free fatty acid(FFA) from peripheral depot ${ }^{47}$.Interestingly, most of the studies with different plantextracts in diabetic rats were in agreement with our result ${ }^{48}$. The rise in serum TG, TC, and low HDL in this study indicate derangement oflipid metabolism and amplified incidence of cardiacdysfunction in diabetic rats. Insulin deficiency or resistancemay be responsible for dyslipidemia, becauseinsulin has an inhibitory action on HMG-COA reductase, a key enzyme which is responsible for the metabolism ofLDL particles rich in cholesterol.

Administration of aqueousextracts of Cinnamon, green coffee and black coffeeshowed significant decreasein TC and TG. This alleviationdenotes the anti-hyperlipidaemic potential of Cinnamon, green coffee and black coffee.Cinnamonin reversing the elevation of TCand TG and increased HDL-c in hyperlipidaemicrats agrees with the findings of ${ }^{39}$ for diabetic and hyperlipidaemic rats. The lipid lowering effect of Cinnamon, green coffee and black coffee in all treated groups might be due to insulin potentiating action of cinnamon ${ }^{49}$. Usually when glucose metabolism is improved lipid metabolism is also improved. There are no references about effect of the double combination treated groups and triple combination treated groups on hyperglycemia and hyperlipidemia in the recent studies. Our study was unique in that it was also designed to examine deduction of better methods of herbal treatment comparison between treatments alone or by mixing herbs together. In this study, we found that the mix of herbs is better than using herbs alone where the triple combination treated group is more effective than double combination treated groups (cinnamon\& green coffee and cinnamon \& black coffee) than single treated groups in the same time period on Streptozotocin induced diabetic rats. 


\section{CONCluSion}

The recommendation of the our study to use the triple combination treatment by cinnamon, green and black coffee due to it is the best group that acts as anti-hyper glycemia, antihyperlipidemia

\section{REFERENCES}

[1] American Diabetes Association. Standards of Medical Care in Diabetes (2017). Diabetes Care. 40.

[2] American Diabetes Association. Standards of Medical Care in Diabetes (2015). Diabetes Care. 38.

[3] Ghorbani A. (2013): Best herbs for managing diabetes: A review of clinical studies. Braz J Pharm Sci 49:413-422.

[4] Jung M, Park M, Lee H.C, Kang Y.H, Kang E.S and Kim S.K. (2006): Antidiabetic agents from medicinal plants. Curr Med Chem 13: 1203-1218.

[5] Achaya D and Shrivastava K.(2008): Indigenous Herbal Medicine: Tribal Formulations and Traditional Herbal Practices. Aavishkar Publishers Distributors, Jaipur, Indian. 440.

[6] Vuksan V and Sievenpiper JL (2005): Herbal remedies in the management of diabetes: lessons learned from the study of ginseng. Nutr Metab Cardiovasc Dis 15: 149-160.

[7] Abdel-Azim N.S, Shams K.A, Shahat A.A.A, El-Missiry M.M, Ismail S.I and Hammouda F.M. (2011): Egyptian herbal drug industry: challenges and future prospects. Res J Med Plant .5: 136-144.

[8] Shah A.H, AL-Shareef A.H, Ageel A.M, Qureshi S. (1998): Toxicity studies in mice of common spices Cinnamomum zeylanicum bark and piper lonum fruits. Plant Foods Hum Nutr; 52:231-239.

[9] Awanish, M., Rajbir, B., Amarjit, S., Mohan,P and Singh,I.(2010): Ameliorative effect of the cinnamon oil from Cinnamomum zeylanicum upon early stage diabetic nephropathy. Planta Med. 76(5): 412-417.

[10] Nir Y, Potasman I, Stermer E, Tabak M, Neeman I. (2000): Controlled trial of the effect of cinnamon extract on Helicobacter pylori. Helicobacter.5:94-97.

[11] Calnan CD (1976): Cinnamon dermatitis from an ointment. Contact Dermatitis.2:167-70.

[12] Kamath J.V, Rana A.C, Chowdhury A.R. (2003): Pro-healing effect of cinnamomum zeylanicum bark. Phytother Res.18:970-972.

[13] Skidmore-Roth L. 2nd ed. St. Louis: Mosey; (2002): Handbook of herbs and natural supplements; p. 38.

[14] Altschuler J.A, Casella S.J, MacKenzie T.A, Curtis K.M (2007): The effect of cinnamon on A1C among adolescents with type 1 diabetes. Diabetes Care30:813-816.

[15] Frydman-Marom A, Levin A, Farfara D, Benromano T, Scherzer-Attali R, Peled S, Vassar R, Segal D, Gazit E, Frenkel D and Ovadia M.(2011) :Orally administrated cinnamon extract reduces beta-amyloid oligomerizationand corrects cognitive impairment in Alzheimer's disease animal models.PLoS One 6: e16564.

[16] Shimada Y, Goto H, Kogure T, Kohta K, Shintani T, Itoh T and Terasawa K. (2000): Extractprepared from the bark of Cinnamomum cassia Blume prevents glutamateinducedneuronal death in cultured cerebellar granule cells. Phytother Res 14:466-468.

[17] Schoene N.W, Kelly M.A, Polansky M.M, Anderson R.A.( 2005): Water-soluble polymeric polyphenols from cinnamon inhibit proliferation and alter cell cycle distribution patterns of hematologic tumor cell lines. Cancer Lett; 230:134-140.

[18] Odiase D.E and Erhunmwunse M.O. (2014): Histological Effects of Aqueous Extract of Cinnamon on the Kidney Functions of Adult Wistar Rats. SMU Medical Journal,Volume - 1, No. 2, July.

[19] Parliament and T.H, (2000):An Overview of Coffee Roasting. In: Parliament, T.H., C.T. Ho and P. Schieberle (Eds.), Caffeinated Beverages: Health Benefits, Physiological Effects and Chemistry. Proceeding of the ACS Symposium Series 754. American Chemical Society, Washington, DC, pp: 188-201. 
[20] Delgado-Andrade, C. and Morales F. J.,(2005): Unraveling the contribution of melanoidins to the antioxidant activity of coffee brews. J. Agric. Food Chem., 2005, 53 (5), pp 1403-1407.

[21] Gaafar M. Ahmed and Heba E. El-Ghamery and Mahmuod F. Samy (2013): Effect of Green and Degree of Roasted Arabic Coffee on Hyperlipidemia and Antioxidant Status in Diabetic Rats, Adv. J. Food Sci. Technol., 5(5): 619-626.

[22] Uchiyama S and Yamaguchi M. (2003): Alteration in serum and bone component findings induced in streptozotocin-diabetic rats is restored by zinc acexamate. International Journal of Molecular Medicine, 12: 949-954.

[23] Caraway WT, Watts N.B. Carbohydrates In: Tietz NW, ed (1987): Fundamentals of Clinical Chemistry. 3ry ed. Philadephia WB saundes:422-447.

[24] Eastham and R.D. (1985): Biochemical values in clinical Medicine, $7^{\text {th }}$ Ed. Bristol. England. John Wright \& Sons, Ltd.

[25] Wallace TM, Levy JC, Matthews DR. (2004): Use and abuse of HOMA modeling. Diabetes Care; 27: 1487-1495.

[26] Rautela G.S and Liedtke R.J. (1978): Automated enzymic measurement of total cholesterol in serum, ClinChem .108-114.

[27] Rifai N, Russell Warnick G, Dominiczak M.H. (1997): Handbook of Lipoprotein Testing. AACC Press, Washington, DC, p. 115.

[28] Genest J, 2002: Genetics and prevention: a new look at high density lipoprotein cholesterol. Cardiol. In Rev. 10(1):61-71.

[29] Zare K, FatemiTabatabaei SR, Shahriari A, Jafari RA.(2012): The effect of butter oil on avoidance memory in normal and diabetic rats. Iran J Basic Med Sci 2012; 15:983-989.

[30] Whiting DR, Guariguata L, Weil C, Shaw J. (2011): IDF diabetes atlas: global estimates of the prevalence of diabetes for 2011 and 2030. Diabetes Res ClinPract 2011; 94:311-321.

[31] Gomez-Perez F.J, Aguilar-Salinas C.A, Almeda-Valdes P, Cuevas-Ramos D, Lerman Garber I, Rull J.A.(2010): HbA1c for the diagnosis of diabetes mellitus in a developing country. Arch Med Res 4:302-308.

[32] Yilmaz O, Ersan Y, DilekOzsahin A, Ozturk AI, Ozkan Y.(2013): Consequences of the combined $\alpha$-tocopherol, ascorbic acid and $\alpha$-lipoic acid on the glutathione, cholesterol and fatty acid composition in muscle and liver of diabetic rats. Iran J Basic Med Sci; 16:165-172.

[33] Chander AP, Reddy RRA, Puchchakayala G.(2011): Hypoglycemic and antidiabetic activity of glochidionvelutinum on streptozotocin-nicotinamide induced Type 2 diabetic rats. Eur $\mathbf{J}$ BiolSci 3:126-130.

[34] Kumar S, Rashmi N, Kumar D. (2010): Evaluation of antidiabetic activity of Euphorbia hirta Linn in streptozotocin induced induced diabetic mice. Indian J Nat Prod Resour1:200-203.

[35] Ghorbani A. (2013): Best herbs for managing diabetes: A review of clinical studies. Braz J Pharm Sci 49:413-422.

[36] Yang, H., Fan, S., Song, D., Wang, Z., Ma, S., Li, S., Li, X., Xu, M., Xu, M. and Wang, x. (2013): Long-term streptozotocin-induced diabetes in rats leads to severe damage of brain blood vessels and neurons via enhanced oxidative stress. Mol. Med. Report. 7(2): 431-440.

[37] Konrad, R.J., Mikolaenko, I., Tolar, J.F., Liu, K. and Kudlow, L.E (2001): The potential mechanism of the diabetogenic action of Streptozotocin : inhibition of pancreatic beta-cell OGlcNAc-selective N-acetyle-beta-D-glucosaminidase. Biochem.J. 356: 31-41.

[38] Weiss and R.B (1982): Streptozotocin: A review of its pharmacology, efficacy and toxicity. Cancer Treat. Rep. 66(3) : 427-438.

[39] Kim S.H, Hyun S.H, Choung S.Y. (2006): Antioxidative effects of Cinnamomicassiae and Rhodiolarosea extracts in liver of diabetic mice. Biofactors. 26(3): 209-219.

[40] Anderson R.A, Broadhurst C.L, Polansky M.M, Schmidt W.F, Khan A, Flanagan V.P, Schoene N.W, Graves D.J (2004): Isolation and characterization polyphenol type A polymers from cinnamon with insulin-like biological activity. Journal of agricultural and food chemistry 52: $65-70$. 
[41] Hlebowicz J., Darwiche G., Bjorgell O. and Almer L.O., (2007): Effect of cinnamon on postprandial blood glucose, gastric emptying and satiety in healthy subjects. Am. J. Clin. Nutr., 85: 1552-1556.

[42] arvill-Taylor K.J, Anderson R.A, Graves D.J. (2001): Ahydroxychalcone derived from cinnamon functions as a mimetic for insulin in 3T3-L1 adipocytes. J Am CollNutr. 20(4):327336.

[43] Cao H., Graves D.J.and R.A. Anderson (2010): Cinnamon extract regulates glucose transporter and insulin-signaling gene expression in mouse adipocytes. Phytomed., 17: 10271032 .

[44] Jitomir J and Willoughby DS. (2009): Cassia cinnamon for the attenuation of glucose intolerance and insulin resistance resulting from sleep loss. J Med Food;12(3): 467-472

[45] Shearer J, Farah A, de Paulis T, Bracy D.P, Pencek R.R, Graham T.E,Wasserman D.H.( 2003): Quinides of roasted coffee enhance insulin action in conscious rats. J Nutr; 133: 35293532.

[46] Koffi, M.C; de la Providencia, I.E; Elsen, A; Declerck, S. (2009): Development of an in vitro culture system adapted to banana mycorrhization. AFRICAN JOURNAL OF BIOTECHNOLOGY, 8 (12):2750-2756.

[47] Krishnaveni MS, Mirunalini K, Karthishwaran G, Dhamodharan N (2010): Antidiabetic and antihyperlipidermic properties of phyllanthusembicalinn (Euphobiaceae) on sterptozotocin induced diabetic rats. Pak. J. Nutr. 9:43-51.

[48] Ladan M.J, Umar R.A, Hassana S.W, Shehu B (2007): Glycemic status and lipid profiles of diabetic in Sokoto, Nigeria. Asia. J. Biochem.2:183-187.

[49] Khan A, Bryden N.A, PolanskyM.M,. Anderson R.A. (1990): Insulin potentiating factor and chromium content of selected foods and spices. Biol Trace Elem Res 24:183-188.

Citation: F. Abdel Hamid, "Some Natural Plants in Glycemic Amelioration in Streptozotocin Induced Rats", International Journal of Clinical Chemistry and Laboratory Medicine (IJCCLM), vol. 3, no. 2, p. $27,2017$. http://dx.doi.org/ 10.20431/2455-7153.0302003

Copyright: (C) 2017 Authors. This is an open-access article distributed under the terms of the Creative Commons Attribution License, which permits unrestricted use, distribution, and reproduction in any medium, provided the original author and source are credited. 